\title{
A LITERATURA DE MONTEIRO LOBATO NA DISCUSSÃO DE QUESTÕES ACERCA DA NATUREZA DA CIÊNCIA NO ENSINO FUNDAMENTAL
}

\author{
Silvia Regina Groto* \\ André Ferrer P. Martins**
}

RESUMO: Neste artigo, analisamos determinados aspectos das visões de ciência presentes em três obras da literatura de Monteiro Lobato, visando à utilização desse material na discussão de questões acerca da natureza da ciência em aulas de ciências. A análise das obras Reinações de Narizinho, A reforma da natureza e A chave do tamanho evidenciou a presença de trechos associados ao conhecimento científico que foram classificados em quatro categorias: linguagem científica, visão de cientista, método científico e valoração da ciência. Embora as histórias tragam elementos de visões de ciência consideradas inadequadas segundo alguns estudos da área da Didática das Ciências, consideramos que as obras poderiam ser utilizadas no Ensino Fundamental, principalmente para a problematização das visões de ciência e de cientista que veiculam.

Palavras-chave: Monteiro Lobato. Natureza da Ciência. Literatura.

\section{THE LITERATURE OF MONTEIRO LOBATO TO DISCUSS NATURE OF SCIENCE ISSUES AT ELEMENTARY SCHOOL}

ABSTRACT: In this article, we analyze certain aspects of the views of science presented in three works of Monteiro Lobato's literature. Our aim is to use this material to discuss issues regarding Nature of Science in science classes. The analysis of the works of Reinaçoes de Narizinho, A Reforma da Natureza and A Chave do Tamanho revealed the presence of excerpts associated with the scientific knowledge that have been classified into four categories: scientific language, view of scientist, scientific method and appreciation of science. While the stories bring elements of science views considered inadequate according to some studies from Science Education, we believe that these works could be used at elementary school, especially for questioning the views of science and scientist they provide.

Keywords: Monteiro Lobato. Nature of Science. Literature.

DOI - http://dx.doi.org/10.1590/1983-21172015170206 
A 1 iteratura de monteiro 1obato na discussão de questões acerca da natureza da ciência no ensino fundamental

\section{LA LITERATURA DE MONTEIRO LOBATO EN LA DISCUSIÓN DE CUESTIONES ACERCA DE LA NATURALEZA DE LA CIÊNCIA EN LA ENSEÑANZA FUNDAMENTAL}

RESÚMEN: En este artículo, analizamos determinados aspectos de las visiones de ciencias presentes en tres obras de la literatura de Monteiro Lobato, buscando la utilización de este material en la discusión de cuestiones acerca de la naturaleza de la ciencia en clases de ciencias. El análisis de las obras "Travesuras de Naricita", "La Reforma de la Naturaleza" y "La Llave del Tamaño" evidenció la presencia de trechos asociados al conocimiento científico que fueron clasificados en cuatro categorías: lenguaje científico, visión de científico, método científico y valoración de la ciencia. Aunque las historias traigan elementos de visiones de ciencia consideradas inadecuadas segundo algunos estudios del área de la Didáctica de las Ciencias, consideramos que las obras podrían ser utilizadas en la Enseñanza Fundamental, principalmente para la problematización de las visiones de ciencia y de científicos que vehiculan.

Palabras clave: Monteiro Lobato. Naturaleza de la Ciencia. Literatura. 


\section{INTRODUCุão}

Parte da linguagem a que estamos expostos na sociedade contemporânea é a linguagem científica. Ao mesmo tempo, o conhecimento produzido pela ciência e o status de autoridade a ela conferido são utilizados, muitas vezes, na validação de algumas decisões econômicas, políticas, culturais e sociais de interesse coletivo. Nesse sentido, saber ciência contribui para que o homem estabeleça um diálogo inteligente com mundo, possibilitando que ele se posicione de modo crítico perante tomadas de decisões em situações que envolvam o conhecimento científico.

Documentos oficiais da educação brasileira, como os Parâmetros Curriculares Nacionais (PCN), referendam essa importante dimensão do saber ciência. Segundo esses documentos, conhecer ciência amplia a possibilidade de participação social do homem e o seu desenvolvimento mental, viabilizando a sua capacidade de exercer a cidadania. Dessa forma, o ensino de ciências deve "oportunizar ao aluno a capacidade de elaborar juízo sobre riscos e benefícios das práticas científico-tecnológicas" (BRASIL, 1998, p. 33) para que ele possa se posicionar conscientemente frente a algumas questões que lhe são postas pelo mundo. Mas o que deve ser privilegiado pelo ensino de ciências visando oportunizar a participação dos alunos nas tomadas de decisões relevantes que envolvam o conhecimento científico, habilitando-os ao exercício da cidadania?

Uma das possíveis respostas a essa pergunta envolve o ensino sobre a ciência por meio da inserção de temas relativos à natureza da ciência $(\mathrm{NdC})$ nos currículos. De modo geral, há certo consenso de que ensinar sobre a ciência é tão importante quanto ensinar ciência (MATTHEWS, 1995; CACHAPUZ et al., 2005; ADÚRIZ-BRAVO; ROSALES, 2011). Notadamente, os estudos que defendem a inserção da $\mathrm{NdC}$ no ensino argumentam em favor da sua importância para a formação cidadã, uma vez que saber sobre a ciência auxiliaria na "formação de cidadãos susceptíveis de participar na tomada fundamentada de decisões em torno de problemas sócio-científicos e sócio-tecnológicos" (CAPACHUZ et al., 2005, p. 17). Silva e Gastal (2011, p. 36) também compartilham desse pensamento. As autoras defendem que, para formar o cidadão, "o ensino de ciências deve ser acompanhado por reflexões sobre a natureza do processo científico, seus métodos e suas relações com os condicionantes sociais. Uma posição crítica em relação ao fazer científico e seus produtos habilita o aluno ao pleno exercício de sua cidadania".

Por outro lado, trabalhos têm evidenciado que o ensino transmite visões de ciência inadequadas, distorcidas ou mesmo empobrecidas, que dificultam o entendimento do funcionamento da prática científica e da construção dos conhecimentos científicos, gerando obstáculos para a compreensão de conceitos e contribuindo para o desinteresse dos alunos. Nessa linha de raciocínio, Gil Pérez et al. (2001) apontam sete visões equivocadas manifestas por professores e alunos em diversos níveis de ensino: a visão empirico-indutivista e ateórica, que apresenta uma 
compreensão ingênua do desenvolvimento científico, como se ele fosse derivado, por via indutiva, apenas de observações e experimentações "neutras", isto é, sem a influência de pressupostos teóricos ou hipóteses a priori; a visão rígida (algorítmica, exata, infalivel), associada à existência de um "método científico" único, rigoroso, de caráter quantitativo, formado por etapas fixas e previamente definidas que devem ser necessariamente seguidas e que conferem à ciência um status de conhecimento "provado" e verdadeiro; a visão aproblemática e a-histórica da ciência, que omite os problemas e os contextos que geraram as investigações, dificultando o entendimento da ciência como um empreendimento resultante de um processo histórico; a visão exclusivamente analítica, que transmite a ideia de uma ciência compartimentalizada, desconsiderando os esforços de unificação do conhecimento; a visão acumulativa de crescimento linear, na qual a ciência é percebida como o resultado de um acúmulo sucessivo e gradual de conhecimentos ao longo do tempo, estando associada à ideia do "progresso da ciência" - uma visão simplista que omite os períodos de crises, revoluções, rupturas e mudanças de paradigmas; a visão individualista e elitista, geralmente associada à existência de "gênios" e que dificulta o entendimento do caráter coletivo e cooperativo da ciência; e a visão socialmente neutra, que transmite a ideia de uma ciência isenta da interferência de fatores externos, como questões políticas, econômicas, religiosas e éticas, por exemplo. Embora esse conjunto de sete visões seja, até certo ponto, uma "caricatura” e uma simplificação, ilustra elementos característicos daquilo que poderia ser chamado de visão de "senso comum" da ciência e de seu desenvolvimento.

A inclusão de questões relativas à $\mathrm{NdC}$ no ensino não é recente, estando incorporada à legislação educacional de diversos países (NATIONAL RESEARCH COUNCIL, 2013; DEPARTMENT FOR EDUCATION, 2013). No Brasil, os PCN (BRASIL, 1998) recomendam o início da abordagem de alguns aspectos da atividade científica no Ensino Fundamental. De modo geral, os alunos, nesse nível de ensino, devem compreender a ciência como uma atividade humana, coletiva, historicamente construída e relacionada a aspectos sociais, econômicos, políticos e culturais. Os documentos salientam, ainda, a imprecisão de se apresentar a ciência como possuidora de um método único e como resultado de ações individuais. Mais especificamente, durante o $3^{\circ}$ ciclo do Ensino Fundamental $\left(6^{\circ}\right.$ e $7^{\circ}$ anos), os PCN recomendam que o professor enfatize a ciência como uma construção humana e coletiva, deixando outros aspectos mais complexos da prática científica para serem abordados no próximo ciclo. O $4^{\circ}$ ciclo do Ensino Fundamental ( $8^{\circ}$ e $9^{\circ}$ anos) deve propiciar outras reflexões sobre o fazer da ciência, tais como a compreensão a respeito das contribuições recíprocas que acontecem entre o desenvolvimento científico e os aspectos socioculturais de modo geral e o entendimento do desenvolvimento da ciência numa perspectiva não cumulativa. Mas como o professor pode abordar essas questões no Ensino Fundamental? São questões complexas que, na maioria das vezes, demandam adaptações para que possam ser trabalhadas nesse nível de ensino.

Temas relativos à $\mathrm{NdC}$ têm sido frequentemente abordados, no ensino, 
por meio de enfoques históricos, filosóficos ou sociológicos. Tais enfoques, em princípio, podem "humanizar as ciências e aproximá-las dos interesses pessoais, éticos, culturais e políticos da comunidade; podem tornar as aulas de ciências mais desafiadoras e reflexivas, permitindo, desse modo, o desenvolvimento do pensamento crítico" (MATTHEWS, 1995, p. 165). Mas essa não é a única perspectiva possível. Neste trabalho, propomos que questões acerca da $\mathrm{NdC}$ sejam abordadas no ensino por meio de outro enfoque, o literário.

Diversos são os autores que têm sugerido o trabalho com a literatura no ensino de ciências (ZANETIC, 1997; PINTO; RABONI, 2005; SALOMÃO, 2008; GUERRA; MENEZES, 2009). De modo geral, argumenta-se que a literatura motivaria os alunos, estimularia a curiosidade, contextualizaria e problematizaria os conteúdos científicos presentes nas obras literárias, contribuiria para a apropriação da linguagem científica, além de possibilitar, ao aluno, a ampliação da sua "visão de mundo", uma vez que, por meio da literatura, ele entraria em contato com diferentes realidades. Não é nosso intuito, neste trabalho, detalhar essas diversas dimensões do trabalho com a literatura no ensino de ciências. Interessa-nos, entretanto, o fato de alguns textos literários transmitirem visões de ciência vinculadas ao contexto histórico da época em que foram produzidos, de modo que poderiam ser utilizados na problematização e na reflexão sobre essas mesmas visões de ciência que veiculam, contribuindo para a construção de visões mais adequadas, menos distorcidas e empobrecidas da atividade científica. Como esclarece Zanetic (2006), a relação entre a ciência e a literatura é mais complexa do que aparenta ser, uma vez que parece haver uma influência mútua entre ambas: o pensamento científico dominante exerceria influência sobre alguns escritores que se tornariam corresponsáveis pela sua disseminação em uma determinada época e os escritores antecipariam características do pensamento científico de outras épocas, tornando-se, também, corresponsáveis pelo seu desenvolvimento, de modo que “'as ‘visões de mundo’ da ciência, na sua evolução, vão paralelas, e se influenciando mutuamente, com as 'visões de mundo' dos personagens literários” (ZANETIC, 1997, p. 32).

No Ensino Fundamental ( $3^{\circ}$ e $4^{\circ}$ ciclos), o trabalho com a literatura infanto-juvenil é particularmente relevante, uma vez que possibilita a abordagem dos conteúdos científicos de forma lúdica, atraindo a atenção de um maior número de alunos. Dentre os literatos brasileiros, Monteiro Lobato destaca-se pela constante presença da ciência em suas obras. Também por essa razão, alguns autores sugerem o trabalho com a literatura infantil de Lobato no ensino de ciências (CARVALHO, 2007; SILVEIRA, 2010; SANTOS, 2011; GROTO 2012; OLIVEIRA; GOLDFARB, 2012; GROTO; MARTINS, 2015a). Além de nós mesmos (MARTINS; GROTO 2012; GROTO; MARTINS 2015b), alguns desses autores, de diferentes formas, têm discutido a visão de ciência manifesta em determinadas obras (SANTOS, 2011; SILVEIRA, 2013). Neste artigo, buscamos evidenciar como a literatura de Monteiro Lobato poderia contribuir para a abordagem de algumas questões acerca da Natureza da Ciência no Ensino Fundamental. Para isso, anali- 
samos três obras da literatura lobatiana (Reinações de Nariz̧inho, A reforma da naturez̧a e A chave do tamanho), dialogando com alguns trabalhos da área da Didática das Ciências Naturais que se preocupam com a temática da Natureza da Ciência.

$\mathrm{Na}$ próxima seção, justificamos a escolha por Monteiro Lobato e pelas três obras mencionadas anteriormente, realizando uma breve descrição das mesmas. Logo após, fazemos a análise das visões de ciência presentes nessas obras, visando à possível utilização desse material na abordagem de determinadas questões acerca da NdC nas aulas de ciências do Ensino Fundamental II.

\section{Monteiro Lobato: um escritor com veia científica}

A literatura pode ser utilizada nas aulas de ciências por meio de duas categorias de autores, segundo Zanetic (2007): os “cientistas com veia literária", isto é, aqueles que estão diretamente envolvidos na prática científica e cujos textos podem ser "lidos" como literatura, e os "escritores com veia científica", que fazem uso do conhecimento científico na escrita de suas obras. Monteiro Lobato é considerado um autor brasileiro com "veia científica", o que pode ser facilmente observado pela análise de suas obras, sejam elas adultas ou infantis, que evidencia a ênfase dada por ele às relações estabelecidas entre o homem e a ciência. Mas qual seria o motivo de tamanho interesse pela Ciência?

Alguns autores relatam a influência que certos professores exerceram sobre o interesse de Monteiro Lobato pela ciência, notadamente a do positivista Mostardeiro, professor de Lobato durante a sua adolescência em Taubaté, e a dos mestres progressistas da Faculdade de Direito do Largo do São Francisco, durante a sua juventude em São Paulo. Os últimos contribuíram, principalmente, para as ideias sobre evolucionismo e cientificismo que permeiam muitas das suas obras (PENTEADO, 1997). A influência do primeiro, de certa forma, é evidenciada por Lajolo (2006) ao relatar o reencontro do antigo mestre com o ex-aluno, recém-formado Bacharel em Direito. Segundo Lajolo, eles discutiram sobre "as novas filosofias" que Lobato conhecera em São Paulo. Mostardeiro lhe sugere o aprofundamento da leitura de diversos autores, dentre eles, Herbert Spencer e Augusto Comte. Relata Cavalheiro (1955), seu principal biógrafo, que, após o reencontro, Lobato passou

\footnotetext{
a bracejar na ciência, embebendo-se de positivismo, de evolucionismo, de materialismo, de darwinismo, de monismo, heterogeneamente, precipitada e loucamente, com ânsia de um espírito que quebrou algemas e partiu em liberdade. Não sabia o que estava procurando, mas a curiosidade levava-o a devorar páginas e páginas. (CAVALHEIRO, 1955, p. 78)
}

As "novas filosofias" que lhe foram apresentadas durante a época da $\mathrm{Fa}$ culdade de Direito parecem ter influenciado, também, a participação de Lobato durante as campanhas sanitaristas, iniciadas em 1918 e lideradas, principalmente, por um grupo de médicos (dentre eles, Oswaldo Cruz) considerados, por Lobato, os "homens da ciência", responsáveis pela implantação da "ciência médica" 
que salvaria o Brasil (HABIB, 2003). Nas palavras de Lobato, "o nosso povo, transplante europeu feito em época de magros conhecimentos científicos, foi invadido pela microvida tropical [...]. Só agora se faz o diagnóstico da doença, e surge uma orientação científica para a solução do problema da nossa nacionalidade [...]" (LOBATO, 1918 citado por CAMENIETZKI, 1988, p. 14). A fase em que participou das campanhas sanitaristas permanece envolta em polêmicas, relacionadas, principalmente, às questões raciais. Alguns autores sugerem que dentre os incentivadores das campanhas sanitaristas existiam muitos que almejavam a "higienização racial" do povo brasileiro (HABIB, 2003). As “ideias eugênicas” veiculadas no Brasil, nessa época, derivavam do darwinismo social propagado por vários pensadores europeus, dentre eles, Herbert Spencer, cujo pensamento havia sido apresentado a Lobato ainda durante a época da Faculdade de Direito.

Além da influência exercida por alguns professores no seu "gosto" pela ciência, a experiência que teve nos Estados Unidos, como adido comercial do Brasil, também parece ter sido marcante para Lobato. Ele e a família viveram cerca de quatro anos em Nova Iorque, entre 1927 e 1931. A modernidade, a eficiência e o modo de vida estadunidense o encantaram demasiadamente. Lobato acreditava que o progresso americano era resultado da combinação petróleo-ferro, e seu sonho, após conhecer o modo de produção fordista e as novas tecnologias de beneficiamento de ferro (processo Smith), era trazê-los para o Brasil (PENTEADO, 1997). Em uma carta, relata a um amigo: “[...] sou um peixe que esteve fora d'água desde 1882, quando nasci, e só agora caí nela. Isto aqui é o mar do peixe do Lobato. Tudo como quero, como sempre sonhei [...] Meu plano agora é um só: dar ferro e petróleo para o Brasil" (LOBATO, 1948, p. 302).

Pouco antes de viajar para os Estados Unidos, Lobato lança a obra O presidente negro, considerada uma das primeiras obras de ficção científica brasileira. Essa obra, assim como Caçadas de Pedrinho, tem sido acusada, atualmente, de conter preconceito racial. Apesar da polêmica, Silveira (2010) enfatiza a potencialidade da utilização de O presidente negro no ensino de ciências. Como argumenta o autor, a sua leitura possibilitaria a reflexão sobre algumas questões relevantes da época em que o romance foi escrito, particularmente a industrialização e o eugenismo. Além disso, a obra também poderia contribuir para a discussão de questões mais atuais do ensino de ciências, tais como as relações ciência-tecnologia-sociedade e algumas questões acerca da Natureza da Ciência. Como esclarece Cavalheiro (1955), Lobato, desde 1905, planejava escrever um romance mesclando imaginação, fantasia e futurismo. É assim que o biógrafo descreve essa obra:

a preocupação de Monteiro Lobato foi a de compor um romance, tendo como 'clou' o choque da raça branca com a negra. Esta última, cujo índice de proliferação é maior, alcança a branca, vence-a nas urnas e elege um presidente negro. Através de um enredo fantasioso, em que o autor forceja não só imprimir intensidade dramática 
e amorosa, mas pontilha de audaciosas idéias eugênicas, faz o branco, graças a inteligência, vencer, uma vitória conseguida por intermédio de certos raios inventados pelo Professor Benson. Êsses raios esterilizam os negros sem que eles dêem pela coisa. (CAVALHEIRO, 1955, p. 340, grafia no original)

A obra O presidente negro faz parte da literatura adulta lobatiana. Mas e na literatura infantil como a ciência é abordada pelo autor? Qual a visão de ciência que permeia a obra infantil de Monteiro Lobato? Uma interessante resposta a estas perguntas é dada por Camenietzki (1988). O autor defende que a concepção de ciência manifesta por Lobato ao longo das obras da literatura infantil se modifica ao longo do tempo e pode ser caracterizada em três fases distintas: as obras escritas entre 1920 e 1931/2, pertencem à primeira fase, denominada fase do saber inútil. A ciência representada nesta fase está vinculada ao velho, ao "embolorado", ao saber bacharelesco, à linguagem complicada, representando, muitas vezes, um empecilho ao desenrolar das histórias - Reinações de Narizinho, lançada em 1931, é a obra que melhor representa esta primeira fase. As obras escritas entre 1932/3 e 1940/1, pertencem à segunda fase, na qual a ciência é vinculada a um saber útil. A maior parte da literatura infantil lobatiana pertence a esta fase. É nela que estão presentes todos os livros didáticos, voltados para a escola. Nessas obras, a ciência adquire um status de protagonista em torno da qual as histórias se desenvolvem. Os "sábios", os homens da ciência, são considerados os condutores, salvadores da humanidade. A reforma da natureza (1941) é a obra que caracteriza esta fase. Nas obras escritas entre 1942 e 1947, a fase do saber malversado, a ciência está associada a um conhecimento mal utilizado pelos homens. As obras desta fase discutem acerca das guerras, da utilização dos inventos da ciência para o mal e da estupidez humana. A chave do tamanho (1942) é característica desta fase. Camenietzki (1988) vincula as transformações da concepção de ciência ao longo das obras ao pensamento coletivo e à trajetória de um grupo político do qual Monteiro Lobato fazia parte, o "Grupo do Estado", ligado ao jornal O Estado de São Paulo. O “Grupo do Estado” representava o liberalismo oligárquico paulista que se confrontou com o conservadorismo republicano, sem, entretanto, obter êxito no projeto de implantação dos seus ideais. Nesse sentido, "a obra infantil lobatiana expressa a saga do liberalismo desde o regime oligárquico da Primeira República até o Estado Novo. O veio que demonstra sua trajetória é a visão científica, a forma de expressão literária da ciência, o valor a ela atribuído" (CAMENIETZKI, 1988, p. 79).

Poderiam essas diferentes concepções de ciência presentes na literatura infantil de Monteiro Lobato, como propostas por Camenietzki, dialogar com estudos que abordem a temática da $\mathrm{NdC}$ de modo a contribuir com a sua inserção no Ensino Fundamental? De que forma? Essas são perguntas que procuramos responder neste trabalho por meio da análise das três obras que representam as três fases da concepção de ciência de Monteiro Lobato segundo Camenietzki. 
No Quadro 1 estão detalhadas as obras da literatura infantil de Monteiro Lobato e seus respectivos anos de publicação. Destacamos as obras que são analisadas neste artigo, descritas a seguir.

Quadro 1 - Obras da literatura infantil de Monteiro Lobato

\begin{tabular}{|c|c|c|c|}
\hline \multicolumn{4}{|c|}{ Obras da Literatura Infantil de Monteiro Lobato } \\
\hline obras & ediçào & obras & ediçào \\
\hline OSaci & 1921 & Seröes de Dona Benta* & 1937 \\
\hline Aventuras de Hans Staden & 1927 & O Poço do Visconde* & 1937 \\
\hline Peter Pan & 1930 & Histórias de Tia Nastácia & 1937 \\
\hline Reinações de Narizinho & 1931 & O picapau amarelo & 1939 \\
\hline Viagem ao céu & 1932 & OMinotauro & 1939 \\
\hline Caçadas de Pedrinho & 1933 & Reforma da naturesa & 1941 \\
\hline História do mundo para crianças * & 1933 & A chave do tamanho & 1942 \\
\hline Emilia no pais da gramática * & 1934 & Os doze trabalhos de Hercules & 1944 \\
\hline Aritmética da Emilia * & 1935 & Histórias diversas & 1947 \\
\hline Geografia da Dona Benta ${ }^{*}$ & 1935 & \multirow{4}{*}{$\begin{array}{l}\text { Uma fada modema } \\
\text { A lampreia / O centaurinho } \\
\text { No tempo de Nero } \\
\text { A casa da Emilia }\end{array}$} & \multirow[t]{4}{*}{$*$} \\
\hline História das invençōes * & 1935 & & \\
\hline Memórias da Emilia & 1936 & & \\
\hline D. Quixote das Crianças & 1936 & & \\
\hline
\end{tabular}

Fonte: Adaptado de Lajolo (2006, p. 94).

\section{Reinações de Narizinho}

A obra Reinações de Nariz̧inho (LOBATO, 2009), publicada originalmente em 1931 pela Companhia Editora Nacional (Figura 1), da qual Monteiro Lobato foi editor, reúne vários livros publicados separadamente entre 1920-1931. A ordem dos onze "capítulos” da obra (Quadro 2), cerca de 300 páginas, obedece cronologicamente as datas de publicação desses livros entre 1920 e 1931.

Figura 1 - Capa da obra Reinações de Narizinho (1931)

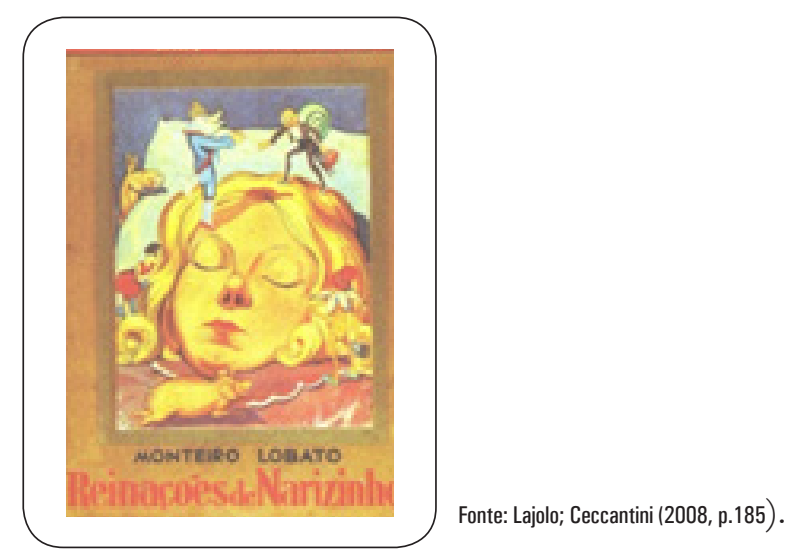


Quadro 2 - Capítulos da obra Reinações de Narizinho

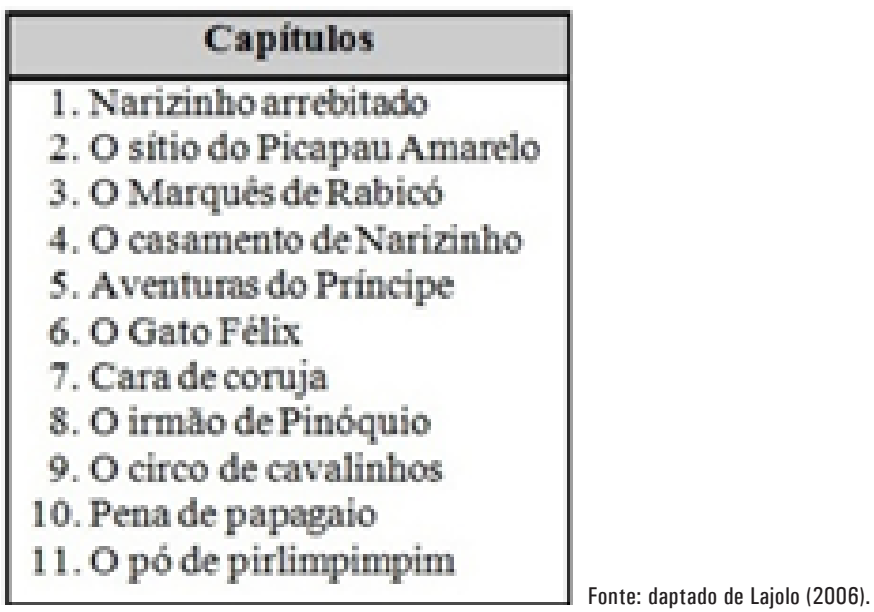

Segundo Bertolucci (2008, p.193), “a unificação da obra em 1931, pelo entrelaçamento de episódios anteriormente publicados, oferece possibilidades amplas de leitura e ainda identifica o texto de Lobato com o modelo de narrativa de composição aberta", possibilitando ao leitor uma sequência própria de leitura. É em Reinações de Narizinho que Monteiro Lobato apresenta aos leitores o Sítio do Pica Pau Amarelo e os seus moradores: Dona Benta, Narizinho, Tia Nastácia, Emília - a boneca que começa a falar após ingerir uma das pílulas do Dr. Caramujo em uma das viagens ao Reino das Águas Claras (Capítulo 1- Narizinho Arrebitado) -, e o Visconde de Sabugosa, o sabugo de milho criado por Pedrinho (Capítulo 3 - O Marquês de Rabicô) especialmente para ser apresentado como o pai do porco Marquês de Rabicó no dia do seu noivado com a boneca Emília. Nos demais capítulos, “a motivação para as várias aventuras parece sempre nascer do desejo das personagens de realizar experiências fantásticas que se misturam à realidade" (BERTOLUCCI, 2008, p.193), seja durante o casamento de Narizinho com o Príncipe Escamado no Reino das Águas Claras (Capítulo 4 - O casamento de Narizinho), na visita do falso gato Félix ao Sítio (Capítulo 6 - O gato Félix), na festa com os personagens famosos dos contos de fadas (Capítulo 7 - Cara de coruja), na construção do Irmão do Pinóquio (Capítulo 8), na criação de O circo de cavalinhos (Capítulo 9) ou ainda quando Dona Benta experimenta pela primeira vez $O$ pó de pirlimpimpim (Capítulo 11).

\section{A reforma da natureza}

A obra A reforma da natureza como a conhecemos hoje (LOBATO, 2010a), é composta de duas partes. Entretanto, ao ser lançada, em 1941 (Figura 2), continha apenas a primeira parte da edição atual. A segunda parte compunha a obra $O$ espanto das gentes, publicada em 1942. Em 1944, pela Editora Brasiliense, 
as duas histórias foram publicadas em um mesmo livro, numa "edição casada". Nas edições posteriores, $\mathrm{O}$ espanto das gentes transformou-se na segunda parte de A reforma da natureza (ABREU, 2008).

Figura 2 - Capa da obra A reforma da natureza (1941)

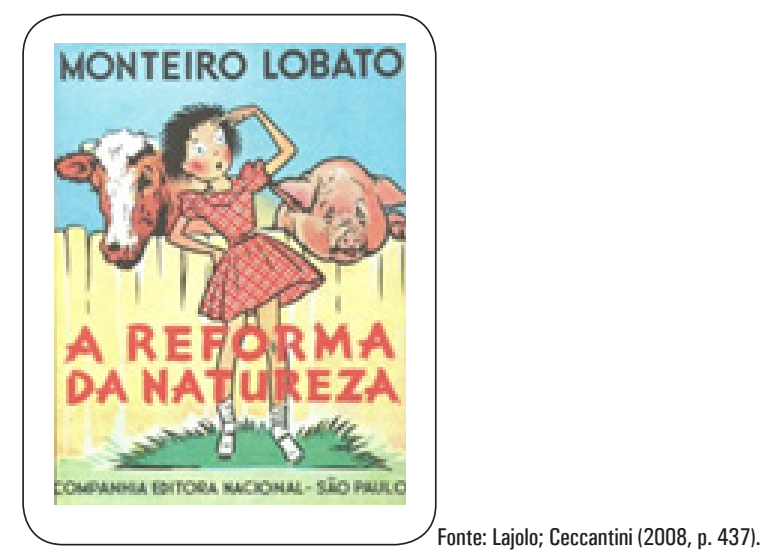

Na primeira parte da obra, Dona Benta e Tia Nastácia são convidadas para auxiliar os ditadores, reis e presidentes no processo de paz, logo após o término da guerra na Europa. Apenas Emília permanece no Sítio, visando aproveitar a oportunidade para colocar em prática o seu antigo plano de reformar a natureza. Com a ajuda de uma amiga vinda do Rio de Janeiro, Emília reforma tudo o que encontra pela frente: os pássaros, os insetos (borboletas, percevejos, moscas, pulgas), a vaca Mocha, o porco Rabicó, as frutas, os livros... Apenas as formigas não são reformadas, pois, segundo a boneca, eram perfeitas! Ao retornar da Europa, Dona Benta faz Emília desfazer a maior parte das reformas. $\mathrm{Na}$ segunda parte da história, Emília decide fazer novas reformas, mas agora com "critérios científicos". Para isso, ela pede ajuda do Visconde de Sabugosa, que aprendera sobre glândulas com os grandes fisiologistas europeus. No laboratório improvisado na cova do anjo, os dois fazem muitos "experimentos científicos" com vários animais. Entretanto, os animais utilizados nas experiências fogem causando grande confusão. O renomado cientista Dr. Zamenhof chega ao Sítio para investigar os estranhos animais vistos nas redondezas. As experiências do Visconde são descobertas. Os animais são capturados e levados para serem estudados pela ciência. Dr. Zamenhof fica impressionado com a inteligência e a grande descoberta do Sabugo, que termina enaltecido pelos seus grandes feitos científicos.

\section{A chave do tamanho}

A obra $A$ chave do tamanho (LOBATO, 2010b) foi publicada em 1942 (Figura 3), quando estava em curso a Segunda Guerra Mundial. Trata-se de uma 
obra especial, afinal, nela, será realizada “a maior reinação do mundo”.

Figura 3 - A chave do tamanho (1942)

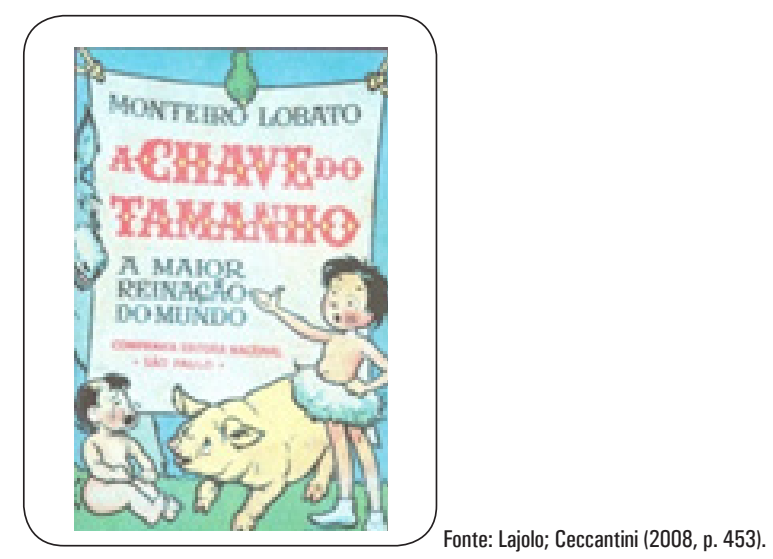

A história tem início quando Pedrinho faz a leitura das manchetes contidas no jornal do dia: “- Novo bombardeio em Londres, vovó. Centenas de aviões voaram sobre a cidade. Um colosso de bombas. Quarteirões inteiros destruídos. Inúmeros incêndios. Mortos à beça" (LOBATO, 2010b, p.15). Dona Benta reage, dizendo:

Uma bomba que cai numa casa de Londres e mata uma vovó de lá, como eu, e fere uma netinha como você, ou deixa aleijado um Pedrinho de lá, me dói tanto como se caísse aqui. É uma perversidade tão monstruosa, isso de bombardear inocentes, que tenho medo de não suportar por muito tempo o horror dessa guerra. Vem-me vontade de morrer. (LOBATO, 2010b, p.15)

Emília, inconformada com a tristeza de Dona Benta, resolve "dar cabo da guerra" e com a ajuda do pó de pirlimpimpim vai até o Fim do Mundo, na Casa das Chaves (que regulava o mundo), desligar a chave da guerra. Entretanto, por engano, a boneca desliga a chave do tamanho, "apequenando" toda a humidade. Em seu retorno ao Sítio, Emília, também “apequenada”, vive diversas aventuras no mundo dos animais gigantes. Quase é comida por alguns, pega uma carona em outros e, pelo caminho, filosofa sobre a Lei De Quem Pode Mais (Seleção Natural). Ao chegar à casa do Major Apolinário, descobre que todos haviam sidos comidos pelo gato da família, exceto as crianças, que são adotadas pela boneca. No caminho para o Sítio, Emília ensina aos órfãos os conhecimentos necessários à adaptação ao novo mundo, sempre fazendo referências aos ensinamentos científicos do Visconde de Sabugosa. Quando finalmente consegue chegar ao Sítio, encontra Dona Benta, Tia Nastácia, Pedrinho e Narizinho vivendo sobre uma cômoda, sob a proteção do Visconde (que continua com seu tamanho natural). Ela e Visconde decidem, então, percorrer o mundo para ve- 
rificar se o "apequenamento" havia atingido toda a humanidade. Na Alemanha, encontram soldados apequenados mortos por asfixia debaixo de imensos pedaços de pano (os uniformes nazistas). O Grande Ditador (Hitler) e seus generais são encontrados escondidos em frestas de rodapés e debaixo de móveis, muito assustados com a nova condição humana. Semelhante cenário é encontrado no Japão, na Rússia e nos Estados Unidos (na Casa Branca). Todos os grandes estadistas haviam perdido o poder graças à diminuição do seu tamanho. $\mathrm{Na}$ Califórnia, entretanto, Emília e Visconde encontraram um incrível "núcleo de civilização nova": a Cidade do Balde (Pail City) comandada pelo Dr. Barnes, um cientista, professor de antropologia da Universidade de Princeton (o "sábio de Princeton"). Pail City havia sido "erguida" e mantida, debaixo de um balde, por meio dos conhecimentos de seus ilustres moradores, os cientistas. No final da história, Emília e Visconde retornam ao Sítio e realizam um plebiscito que decide (a contra gosto da boneca) devolver o tamanho à humanidade.

Vários são os autores que discorrem sobre "a maior reinação do mundo". Segundo Valente (2008, p. 460), a guerra "é o assunto central da obra, ponto do qual derivam outros temas igualmente complexos: a relatividade dos valores, o papel da ciência, as relações políticas do momento”. Coelho (2009) reflete sobre uma aparente contradição presente na ação da boneca. Ao reduzir o tamanho das pessoas, Emília justifica a morte de milhares delas pela não adaptação ao novo mundo criado por ela própria. Trata-se, na verdade, da paz pela violência, exatamente o contrário do que propunha a boneca quando reduziu o tamanho das pessoas, isto é, pôr fim à guerra.

Desta forma, a autora argumenta que "a obra A Chave do Tamanho não é, pois, um livro para crianças, mas para a meninada pré-adolescente... Leitura que, entretanto, deve ser orientada para se transformar em matéria de análise crítica do mundo atual e não apenas entretenimento" (COELHO, 2009, p. 148). Em uma nota de rodapé de um livro sobre a obra infantil de Monteiro Lobato (LAJOLO; CECCANTINI, 2008) pode-se ler que João Luís Ceccantini, pesquisador da área da literatura infantil, “[...] até hoje não se recuperou do impacto da leitura - na primeira série primária - de A Chave do Tamanho (1942), de Monteiro Lobato" (CECCANTINI, 2008, p. 67). Por outro lado, a estranheza da narrativa parece cativar alguns leitores. João Zanetic, físico, relata a recepção da obra ao lê-la quando criança:

Essa 'reinação' deve ter provocado uma ruptura na minha compreensão do que significa a leitura. Até então, eu tinha lido brochuras que traziam as aventuras de $O$ gato de botas, Chapeuzinho vermelho e outras similares. A extraordinária aventura inventada por Lobato em 1942, com ingredientes de contos de fadas, mesclados com elementos de ficção científica, motivada pela tragédia humana provocada pela Segunda Guerra Mundial, deixou-me fascinado. Meu amor pelos livros certamente começou naquele momento. (ZANETIC, 2009, p. 285, grifo do autor)

Apesar da estranheza que a obra pode provocar introduzindo temas como guer- 
ra e morte nas histórias infantis, ela aborda importantes questões éticas relacionadas à atuação humana no mundo, possibilitando, entre outras coisas, a problematização e a reflexão sobre o papel da ciência na sociedade contemporânea.

\section{Analisando as obras}

Visando caracterizar as visões de ciência presentes nas três obras, selecionamos os trechos que faziam algum tipo de alusão à atividade científica. Procuramos, em seguida, identificar a ideia central expressa em cada um dos trechos, assim como termos e expressões recorrentes. Dessa maneira, foi possível classificar os trechos em quatro categorias definidas, portanto, a partir da leitura das obras e da identificação de temáticas recorrentes. Foram elas: linguagem científica, isto é, trechos que, de alguma maneira, se referiam à linguagem expressa pela ciência; visão de cientista, contendo trechos que caracterizavam aquele que faz a ciência (apesar de outros personagens também "emprestarem" suas vozes à ciência, Visconde de Sabugosa é o personagem que, na maioria das vezes, desempenha esse papel, sendo considerado o representante da ciência na obra infantil de Monteiro Lobato (PEREIRA, 2006)); método cientifico, com trechos que, de alguma maneira, se referiam à forma como a ciência era realizada, isto é, ao método utilizado pela ciência; e valoração da ciência, representada por trechos nos quais os personagens externavam algum tipo de valor em relação à prática científica. Um determinado trecho poderia ser incluído em mais de uma categoria, na medida em que expressasse mais de uma ideia ou abordasse mais de uma temática.

Os trechos referentes à categoria linguagem cientifica foram identificados notadamente na obra Reinações de Narizinho. Todos eles associavam a ciência à ideia de uma linguagem difícil e complicada e, em sua maioria, estavam associados ao personagem Visconde de Sabugosa. Selecionamos três desses trechos que evidenciam esse entendimento da linguagem científica. No primeiro deles, pertencente ao capítulo "O casamento de Narizinho", após cair atrás da estante e ficar esquecido por três semanas, é assim que Narizinho se refere ao Visconde:

- Este Senhor Visconde - acrescentou a menina - está mudando de gênio. Depois que caiu atrás da estante da vovó e lá ficou esquecido três semanas, embolorou e deu para sábio. Parece que os livros pegaram ciência nele. Fala dificílimo! É só física pra aqui, química pra ali... (LOBATO, 2009, p. 97)

No segundo trecho, do capítulo "As aventuras do príncipe", Narizinho dá notícias do Visconde de Sabugosa ao Príncipe das Águas Claras: "Ficou todo verdinho, coberto por um pó que sujava todo o assoalho [...] Com certeza já morreu [...] O nosso Visconde já andava meio maluco com suas manias de sábio. Ficou tão científico, que ninguém mais o entendia. Só falava em latim, imagine!"' (LOBATO, 2009, p.119). No terceiro trecho, pertencente ao capítulo "O irmão do Pinóquio”, é assim que o desenho feito por Visconde para concorrer no concurso 
de desenhos que escolheria o formato do irmão do Pinóquio é descrito: “o do Visconde saiu tão científico que não se entendia. Era cheio de triângulos copiados da Geometria e tinha no nariz um X de Álgebra” (LOBATO, 2009 p. 188). $\mathrm{Na}$ obra $A$ reforma da natureza, também encontramos trechos (poucos) que fazem referência à linguagem da ciência como difícil e complicada, mas, diferentemente de em Reinações de Narizinho, esses trechos estavam associados à personagem Tia Nastácia. Isso fica evidente no trecho que relata o primeiro encontro entre o Visconde e o Dr. Zamenhof, cientista que voltaremos a mencionar mais à frente:

\footnotetext{
Veio o café com bolinhos. O barbudo tomou-o e foi assentando as ideias. Minutos depois estava de braço dado ao Visconde, passeando pela sala e absorvido numa profundíssima conversa sobre glândulas. - Ando interessado em descobrir a verdadeira função da Glândula Pineal - dizia o Visconde. - Credo! Exclamou Tia Nastácia, que tinha vindo tirar a bandeja do café. - Até assusta a gente essa linguage'... (LOBATO, 2010a, p. 64)
}

De certa forma, percebe-se também na obra $A$ Reforma da Natureza uma preocupação de se justificar a linguagem complicada da ciência. Assim, o narrador explica em um momento específico da história: "endocrinologista é o nome dos sábios que estudam as glândulas do corpo. O nome é feio, comprido e difícil, mas a coisa é boa" (LOBATO, 2010a, p. 53).

Os trechos classificados na categoria visão de cientista aparecem nas três obras, na maioria das vezes, associados ao personagem Visconde de Sabugosa. A forma como ele é percebido pelos demais personagens apresenta certos elementos comuns e outros diferentes nas três obras. Em todas elas Visconde é considerado um sábio, isto é, um ser muito inteligente. Em Reinações de Narizinho e em A chave do tamanho outro termo muito associado ao Visconde de Sabugosa é 'distraído'. Nessas duas obras, Visconde é descrito como um sábio muito distraído, uma característica de todos os sábios. Isso pode ser evidenciado no trecho a seguir, da primeira obra: "O Visconde era um verdadeiro sábio e os sábios são muito distraídos. Logo que chegou ao alto do mastro, distraiu-se com uma baratinha do mar que andava por ali, ficando a parafusar que nome científico poderia ela ter" (LOBATO, 2009, p. 108). E também neste trecho, da segunda obra, no qual Emília diz: “Os sábios são as criaturas mais distraídas do mundo. Quando o Visconde está ruminando uma ideia qualquer, não ouve nem tiro de canhão, quanto mais um chamadinho meu" (LOBATO, 2010b, p. 69). Ainda em A chave do tamanho, Emília apequenada só consegue a atenção do Visconde de Sabugosa após este acordar de sua "contemplação científica" (LOBATO, 2010b, p. 63). Em Reinações de Nariz̧inho, aos termos sábio e distraído são acrescentados outros termos e ideias, de conotação mais pejorativa: maluco, que só estuda, que só pensa na ciência e nos livros, desleixado, sujo, sem graça/sério. Em A reforma da natureza e em $A$ chave do tamanho surgem outros termos também relacionados à visão de cientista, que são associados ao Visconde e aos outros cientistas (Dr. Zamenhof em A reforma da natureza e Dr. Barnes em $A$ chave do tamanho) que 
aparecem no decorrer das duas histórias. Destacamos: inteligência, persistência, invenção, descoberta. Na segunda parte da obra A reforma da natureza, a atuação do Visconde de Sabugosa, realizando experimentos em seu laboratório improvisado, é o que move a história. Seus feitos científicos atraem outro personagem, o renomado Dr. Zamenhof, “um sábio barbudíssimo, de óculos duplos no nariz" (LOBATO, 2010a, p. 63), que fica espantado ao conhecer o seu colega Visconde. Afinal, “[...] esperava um homem como ele, um sábio de barbas e óculos [...] falam-me de um sábio e apresentam-me um sabugo de cartola! Se eu não mereço respeito, acho que deve ser respeitada a ciência que eu represento" (LOBATO, 2010a, p. 65).

$\mathrm{Na}$ categoria método científico selecionamos trechos que evidenciam, de alguma forma, a percepção dos personagens/autor sobre como a ciência é realizada. Assim, em Reinações de Narizinho, o Dr. Caramujo "trabalha cientificamente [...] antes de tratar o doente o doutor nunca deixava de fazer o diagnóstico" (LOBATO, 2009, p. 27). E Visconde, após examinar, ao microscópio, os pelos do gato que se fez passar pelo gato Félix, diz a Pedrinho: “preciso 'deduzir' e pode ser que esta noite já esteja com o problema resolvido” (LOBATO, 2009, p. 150). No final da primeira parte da obra $A$ reforma da natureza, Dona Benta explica a Emília por que algumas reformas que a boneca realizara na natureza deveriam ser desfeitas. Concordando com os argumentos de Dona Benta, a boneca diz: “[...] agora ela deu uma razão boa, clara, que me convenceu, por isso vou desmanchar o que fiz. Mas com aquele 'vá!' do começo a coisa não ia, não! Vá o Hitler. Vá o Mussolini. Comigo é ali na batata da convicção, do argumento científico!" (LOBATO, 2010a, p. 44). Parte da história se passa no laboratório improvisado do Visconde:

Num instante arrumaram o laboratório, com o binóculo transformado em um excelente microscópio, com vidros vazios, uma lâmina Gillete para fazer de bisturi, várias agulhas e alfinetes, algodão, iodo etc. Emília também arranjou para o Visconde um aventalzinho e um gorro branco, dos que os sábios usam nos laboratórios de verdade. (LOBATO, 2010a, p. 52, grifos nossos)

Além de aspectos relativos ao método, o trecho acima reforça a imagem tradicional do cientista ao fazer referência à indumentária do Visconde.

No laboratório, Visconde faz suas experiências, realizando testes com as glândulas: "[...] passaram a examinar o interior das formigas [...] e depois de descobertas as glândulas, fizeram remeximentos vários, empastelavam umas, misturavam outras, ou enxertavam as glândulas de uma formiga nas de outras [...]" (LOBATO, 2010a, p. 52-53). Algumas saúvas não resistiram, “[...] mas com os aperfeiçoamentos da 'técnica' do Visconde, muitas começaram a salvar-se [...]. Depois que cansaram de operar formigas, iniciaram experiências nos grilos [...]" (LOBATO, 2010a, p. 53). É assim que Visconde responde a Emília, após a boneca descobrir que a enxurrada havia levado todos os pacientes que eles haviam colocado no cercadinho: “- o trabalho da ciência é penoso, minha cara - disse o 
Visconde. - Cumpre recomeçar. Os verdadeiros sábios nunca desistem das suas empresas [...] - Pois vou refazer todas as experiências - disse o abnegado endocrinologista" (LOBATO, 2010a, p. 53). Emília, ao chegar à Casa das Chaves, em A chave do tamanho, alega fazer uso do método experimental do Visconde para descobrir qual a chave da guerra, testando as chaves, ela diz: “- a única solução é aplicar o método experimental que o Visconde usa em seu laboratório. É ir mexendo nas chaves, uma a uma, até dar com a guerra" (LOBATO, 2010b, p. 17). Além do método experimental, Visconde faz uso da observação:

[...] Visconde era um sábio, e os sábios não sabem andar na toada firme e contínua dos ignorantes. $\mathrm{O}$ Visconde andava um pouco e parava para observar qualquer coisa. Aqui um coleóptero novo que ele via pela primeira vez - e ficava de cócoras examinando o bichinho e tomando notas em seu caderno. (LOBATO, 2010b, p. 62).

O método experimental também é utilizado por Dr. Barnes, o cientista que comandava Pail City (a Cidade do Balde). A vida no novo núcleo de civilização se desenvolve por meio de experiências. Uma delas é relatada pelo Dr. Barnes à Emília: “- Estou fazendo uma série de experiências para verificar a melhor substância para tangas - disse o doutor. - Todas as que estão em uso são provisórias e experimentais. Um dos meus companheiros, que é químico, anda pensando numa tanga sintética" (LOBATO, 2010b, p. 108-109).

Analisando os trechos classificados na categoria valoração da ciência, nota-se que, de modo geral, o saber científico é valorizado nas três obras. Em Reinações de Narizinho a ciência é valorizada como conhecimento que, ao ser adquirido, nos torna inteligentes. Isso pode ser evidenciado, por exemplo, em um trecho no qual Pedrinho dialoga com Emília sobre a inteligência de Dona Benta:

[...] Vovó sabe porque lê nos livros e é nos livros que está a ciência de tudo. Vovó sabe mais coisa do mar, sem nunca ter visto o mar, do que este Senhor Caramujo que nele nasceu e mora. Quer ver? [...] - Diga, doutor qual o seu nome científico? [...] - Não sabe, né? [...] Pois fique sabendo que vovó sabe - e até o Senhor Visconde, só porque cheirou os livros e vovó, é capaz de saber [...] O Visconde limpou o pigarro e deitou sabedoria. - O Senhor Caramujo é um molusco gastrópode do gênero Liparis. (LOBATO, 2009, p. 100-101)

Embora a ciência seja valorizada como geradora de conhecimento, de inteligência, a linguagem utilizada por ela é criticada muitas vezes ao longo da obra, como já evidenciamos na categoria linguagem científica. Nessa obra, isso acontece, notadamente, quando a ciência está associada ao personagem Visconde de Sabugosa. Nessas ocasiões a ciência, muitas vezes, passa a representar um saber inútil (CAMENIETZKI, 1988), que "empanturra”. Dessa forma, após Visconde cair atrás da estante e embolorar, ele passava a maior parte do tempo em uma lata (para não sujar o chão com o seu bolor) "lendo, lendo, lendo que 
não acabava mais - e tanto leu que empanturrou" (LOBATO, 2009, p. 207). O Doutor Caramujo é chamado e diagnostica:

\begin{abstract}
- Hum! O caso é dos mais graves. Tenho que operá-lo imediatamente. Sua Excelência está empanturrado de Álgebra e outras ciências empanturrantes. Tragam-me uma bacia d'água, toalha e também uma pedra de amolar [...] - Xi! - exclamou fazendo uma careta. - Vejam só como está este podre ventre. Completamente entupido de corpos estranhos [...] O Doutor Caramujo tomou uma colherzinha e começou a tirar para fora toda aquela tranqueira científica. (LOBATO, 2009, p. 208-209)
\end{abstract}

Na obra $A$ reforma da natureza a ciência é muito valorizada, sendo o motor da segunda parte da história. No laboratório, o sábio Visconde, que aprendera tudo sobre as glândulas com os notáveis cientistas europeus, dá aulas de fisiologia a Emília, explicando sobre o funcionamento de vários sistemas do corpo humano, particularmente o sistema endócrino, e realiza suas fantásticas experiências científicas. $\mathrm{Em} A$ chave do tamanho a ciência também é muito valorizada. De modo geral, é ela que orienta e explica como os desafios do novo mundo dos homens "apequenados" devem ser enfrentados. Isso pode ser evidenciado em alguns trechos que descrevem o retorno da boneca ao Sítio após desligar a chave do tamanho. Ao longo do caminho ela vai encontrando sobreviventes e dando orientações sobre o novo modo de vida, sempre relembrando os ensinamentos científicos do Visconde. Para Dona Nonoca ela diz: “O que temos que fazer é nos adaptar. [...]- Adaptar-se que dizer ajeitar-se às situações [...] Estamos em pleno mundo biológico, onde o que vale é a força ou a esperteza" (LOBATO, 2010b, p. 37, grifo do autor). E para Juquinha: "A professora é uma velha feroz, que não perdoa aos lerdos e preguiçosos. Chama-se Dona Seleção" (LOBATO, 2010 b, p. 49). Em outro momento ela se tranquiliza relembrando o que Visconde lhe havia ensinado sobre os buracos que vai encontrando pelo caminho:

\footnotetext{
[...] foi bom que Visconde me explicasse a origem desses buracos. Muita gente pensa que são buracos de cobra ou outros bichos, mas não são. São 'buracos de raiz'. Quando os homens abrem as estradas, os enxadões dos cavoucadores cortam muitas raízes dentro da terra. Essas raízes cortadas vão apodrecendo e afinal se desfazem em pó de madeira podre, deixando na terra um molde vazio. Os buracos que estou vendo são, portanto, buracos de raiz, e não buracos de bichos. O perigo é o buraco de bicho, porque todos têm dono. (LOBATO, 2010b, p. 59)
}

A valorização da ciência também pode ser percebida na Cidade do Balde, comunidade comandada pelo cientista Dr. Barnes, uma vez que os moradores que lá vivem - dentre eles alguns cientistas - fazem uso dos conhecimentos científicos para conseguirem sobreviver à nova condição humana. Para Dr. Barnes essa era uma oportunidade para se "[...] criar uma nova civilização muito mais agradável que a velha - sem os horrores da desigualdade social da fome, da bliţ̌kriegs e das inúteis complicações criadas pelos inventos mecânicos" 
(LOBATO, 2010b, p. 110, grifo do autor) ${ }^{1}$. Em seu entendimento, a partir da descoberta do fogo e do ferro (o filho do fogo) seguiu-se no velho mundo um desenvolvimento descontrolado: primeiro veio um grande aumento da população humana, uma vez que, com a descoberta do fogo, o homem pode conquistar novos ambientes e obter maior variedade e quantidade de alimentos. Depois veio o ferro "[...] que ia levando a Humanidade ao mais desastroso fim. Que foi a última guerra senão o desabamento em cima do homem de toda uma civilização baseada no ferro, sob a forma de tanques, canhões, fuzis, metralhadoras, bombas aéreas etc.?" (LOBATO, 2010b, p. 111). Desta forma, a ausência do fogo e do ferro causada pelo "apequenamento" dos homens, que estariam impotentes para utilizá-los, isto é, eles “sabem, mas não podem” (LOBATO, 2010b, p. 99, grifo do autor), possibilitaria

construir uma civilização muito mais natural e vantajosa [...] sem guerras, sem máquinas, sem aquele desvario das invenções que nos iam levando para o beleléu [...] Será regressarmos ao período da evolução humana anterior à descoberta do fogo, mas com toda a nossa bela ciência na cabeça - e podemos ser muito mais felizes que os nossos avós daquele tempo. (LOBATO, 2010b, p. 112)

Apesar de as três obras representarem diferentes fases da concepção de ciência de Monteiro Lobato, segundo o entendimento de Camenietzki (1988), nossa análise evidencia que, de modo geral, as obras apresentam visões de ciência que contêm elementos comuns. Em todas as obras a ciência é considerada um conhecimento valorizado, é praticada por pessoas muito inteligentes (os sábios), é possuidora de um método específico e é realizada, principalmente, por meio de observações e experimentações. Nas obras analisadas, os experimentos são realizados, quase sempre, pelo sábio Visconde de Sabugosa que, em seu laboratório (em $A$ reforma da natureza), faz uso de técnicas minuciosas e trabalha persistentemente, rodeado por instrumentos, vidrarias, espécimes/pacientes a serem analisados/examinados.

Embora essas características ilustrem e reforcem, em larga medida, elementos de uma visão de "senso comum" da ciência, é importante destacarmos/ realçarmos aspectos das histórias cujas problematizações poderiam ser exploradas didaticamente. Retomando a própria categorização por nós realizada, diríamos que, do ponto de vista da linguagem científica, as obras reforçam a visão de uma ciência complicada, difícil, esotérica e destinada a poucos. Porém, permite a exploração da ideia de que a ciência apresenta uma linguagem que lhe é própria, característica, e que difere da linguagem cotidiana. A ironia usada por Lobato em muitos trechos e o caráter lúdico das histórias permite que esse aspecto seja problematizado facilmente. De uma linguagem complicada a uma linguagem difícil, mas útil, as referências à linguagem científica refletem, de certa forma, as gradativas transformações da própria relação do autor com a ciência. 
Em relação à visão de cientista e ao método científico, as obras também reforçam, em geral, uma visão de ciência repleta de elementos considerados equivocados. Se retomarmos a classificação de Gil-Pérez et al. (2001), citada na Introdução, vemos que o Visconde de Sabugosa carrega consigo o estereótipo do sábio distraído e sério, que trabalha de modo isolado com os seus equipamentos em um laboratório (ainda que improvisado), reforçando aspectos de uma visão individualista e elitista da ciência. Aliás, a descrição do Visconde, nas três obras, também representa muito bem a visão comum de cientista disseminada na sociedade, de modo geral: sábio, distraído, sério, desleixado, estudioso, que tem barba, usa óculos e avental, e que realiza experiências em seu laboratório. Por outro lado, a surpresa do Dr. Zamenhof ao encontrar o Visconde cria espaço, em sala de aula, para a problematização de uma visão estereotipada do cientista a partir de elementos contidos no próprio enredo da história.

Já o método é associado às observações e experimentações, numa perspectiva que se aproximaria de uma visão empírico-indutivista. Entretanto, não fica claro nas obras o entendimento de que a ciência se desenvolve apenas por observações e experimentações neutras, isto é, sem a utilização de teorias que as orientem. As etapas fixas e rígidas do método científico normalmente presentes na visão rígida da ciência também não aparecem nos textos de Lobato de forma cristalina, mas sim subentendidas pela maneira como o trabalho do Visconde é descrito nas histórias. O trecho anteriormente citado de $A$ chave do tamanho (quando Emília e Visconde chegam à Casa das Chaves) é particularmente problemático, ao associar o método experimental a um procedimento de tentativa e erro. Em seu conjunto, pode-se dizer que elementos do "fazer ciência" estão presentes nas obras e podem ser problematizados e explorados.

Quanto à valoração da ciência, vimos que a perspectiva lobatiana foi se alterando ao longo do tempo, embora a ciência seja sempre considerada um conhecimento valorizado. Particularmente, a obra $A$ chave do tamanho traz elementos relevantes para a problematização da visão socialmente neutra da ciência, como descrita por Gil-Pérez et al. (2001). Ainda que Lobato associe o mau uso da ciência à existência de pessoas más, a obra contribui para o entendimento de que a ciência não é neutra, isto é, não é isenta de interferências externas.

\section{CONCLUSÃO}

As obras da literatura infantil de Monteiro Lobato, um escritor com veia científica, refletem uma visão de ciência vinculada à época em que os livros foram produzidos. Essa visão foi moldada ao longo do tempo por influências diversas e pelas experiências de vida do autor.

Nossos resultados evidenciam que, apesar de a visão de ciência que permeia as obras conter muitos elementos atualmente considerados inadequados para o entendimento da prática científica, as histórias possibilitam introduzir a complexa temática da $\mathrm{NdC}$ nas aulas de ciências do Ensino Fundamental de for- 
ma mais adequada a este nível de ensino, permitindo que esses elementos sejam abordados e problematizados de forma lúdica.

De certa forma, esse entendimento é compartilhado por outros autores que discutem a visão de ciência nas obras de Monteiro Lobato. Santos (2011) e Silveira (2013), por exemplo, nas obras que analisaram ${ }^{2}$, também detectaram a presença de uma visão de ciência que se aproxima da visão empírico-indutivista, tal qual caracterizada por Gil-Pérez et al. (2001). Silveira (2013) aponta a presença de uma visão ingênua de cientista que estaria associada a uma caricatura muito presente no senso comum: o cientista "maluco e com linguagem ininteligível às pessoas comuns” (SILVEIRA, 2013, p. 172). Para além da detecção dessa visão, esse autor, assim como nós, enfatiza a potencialidade das obras infantis lobatianas para a problematização da visão de ciência que expressam, destacando, ainda, o potencial do personagem Visconde de Sabugosa para a problematização da visão de cientista que transmite. Nesse sentido, compreendemos que o encontro entre os "dois cientistas", Visconde de Sabugosa e o Dr. Zamenhof, que acontece na obra $A$ reforma da natureza, como já mencionado, pode ser particularmente interessante para ser trabalhado em sala de aula, visando à problematização dessa visão caricatural de cientista presente no senso comum. Sugerimos, portanto, que as obras que analisamos (Reinações de Narizinho, A reforma da natureza e $A$ chave do tamanho, de Monteiro Lobato) sejam trabalhadas nas aulas de ciências, no Ensino Fundamental, como um veículo problematizador das visões de ciência e de cientista que veiculam. Claro está que é preciso que o professor de ciências esteja preparado para isso.

Entendemos que, para o trabalho aqui proposto com a literatura de Monteiro Lobato, o professor precisa conhecer a obra lobatiana, gostar de - e ler - literatura, compreender a importância de que todos os professores estejam compromissados com a formação de leitores, estar devidamente esclarecido acerca das visões de ciência e de cientistas, bem como dos inúmeros sentidos com os quais esses elementos circulam na cultura e da necessidade da sua problematização no ensino.

Acrescentamos, ainda, que a dimensão lúdica, oferecida pelas obras infantis de Monteiro Lobato, está associada, também, à recepção das suas obras pelos leitores, uma preocupação constante de Lobato como escritor. Na obra A reforma da natureza, por exemplo, essa preocupação fica evidente. O humor, a irreverência, a imbricação real-imaginário e uma linguagem atenta à sua recepção pelos leitores fazem dela uma das obras mais representativas da literatura infantil de Monteiro Lobato. Nesse sentido, é preciso que o professor de ciências, ao trabalhar com as obras lobatianas em sala de aula, garanta aos seus alunos uma experiência de leitura de fruição, para além dos objetivos de leitura crítica em ciências, vivenciando de forma mais plena o trabalho com a literatura no contexto escolar. 


\section{AGRADECIMENTOS}

Os autores agradecem as valiosas contribuições de dois árbitros anônimos. A autora principal agradece à CAPES pelo auxílio financeiro na forma de uma bolsa de mestrado.

\section{NOTAS}

${ }^{1}$ Blitzkriegs, termo alemão que significa "guerra relâmpago". É uma tática de guerra que consiste em um ataque rápido de surpresa evitando que o inimigo tenha tempo hábil para organizar a defesa.

${ }^{2}$ Santos (2011) analisou a obra Serões de Dona Benta. Silveira (2013) analisou 17 obras da literatura infantil de Monteiro Lobato em sua Tese de doutorado.

\section{REFERÊNCIAS}

ABREU. T.C.S. Entre guerras, ciências e reformas: Emília consertando a natureza. In: LAJOLO, M.; CECCANTINI, J. L. (Org.). Monteiro Lobato livro a livro: obra infantil. São Paulo: UNESP; Imprensa Oficial do Estado de São Paulo, 2008. p. 439-451.

ADÚRIZ-BRAVO, A.; ROSALES, S. D. ¿Qué naturaleza de la ciencia hemos de saber los profesores que enseñamos ciencias? Uma questión actual de la investigación didáctica. In: ROSALES, S. F. D.; GATICA, M. R. Q. (Eds.). La enseñanza de las ciencias naturales en las primeras edades: su contribución a la promoción de competencias de pensamiento científico (Volumen 5). Barrancabermeja: Litodigital, 2011, p. 112-128. Disponível em: <http://www7.uc.cl/sw_educ/educacion/grecia/plano/html/ pdfs/biblioteca/LIBROS/LIBROMQSFIN.pdf>. Acesso em: 25-11-2014.

BERTOLUCCI, D. M. da P. Reinações de Narizinho: um livro "estupendo". In: LAJOLO, M.; CECCANTINI, J. L. (Org.). Monteiro Lobato livro a livro: obra infantil. São Paulo: UNESP; Imprensa Oficial do Estado de São Paulo, 2008. p. 187-198.

BRASIL. Ministério da Educação. Secretaria de Educação Fundamental. Parâmetros Curriculares Nacionais: Ciências Naturais $3^{\circ}$ e $4^{\circ}$ ciclos. Brasília: MEC/SEF, 1998.

CACHAPUZ, A. et al. A necessária renovação do ensino de ciências. São Paulo: Editora Cortez, 2005.

CAMENIETZKI, C. Z. O saber impotente: estudo da noção de ciência na obra infantil de Monteiro Lobato. 1988. 99 f. Dissertação (Mestrado em Educação) - Fundação Getúlio Vargas, Rio de Janeiro, 1988.

CARVALHO, F. A. de. Fragmentos Literários para a Educação Ambiental. Revista Eletrônica do Mestrado em Educação Ambiental, Natal, v. 18, p. 336-348, jan./jun. 2007.

CAVALHEIRO, E. Monteiro Lobato: vida e obra. São Paulo: Companhia Distribuidora de Livros; Companhia Editora Nacional, 1955. v. 1 e 2.

CECCANTINI, J. L. De raro Poder Fecundante: Lobato editor. In: LAJOLO, M.; CECCANTINI, J. L. (Org.). Monteiro Lobato livro a livro: obra infantil. São Paulo: UNESP; Imprensa Oficial do Estado de São Paulo, 2008. p. 67-84.

COELHO, N. N. Literatura infantil: teoria análise didática. 7. ed. São Paulo: Moderna, 2009. 
DEPARTMENT FOR EDUCATION. The national curriculum in England. Londres: The National Archives, 2013. 2013. Disponível em:< http://www.gov.uk/dfe/nationalcurriculum>. Acesso em: 03-09-2014

GIL PÉREZ, D. et al. Para uma imagem não deformada do trabalho científico. Ciência \& Educação, Bauru, v. 7, n. 2, p.125-153, 2001.

GROTO, S. R. Literatura de Monteiro Lobato no ensino de ciências. 2012 185f. Dissertação (Mestrado em Educação) - Universidade Federal do Rio Grande do Norte, Natal, 2012.

GROTO, S. R.; MARTINS, A. F. P. Monteiro Lobato em aulas de ciências: aproximando ciência e literatura na educação científica. Ciência \& Educação, Bauru, v. 21, n.1, p. 219-238, 2015 a.

GROTO, S. R.; MARTINS, A. F. P. O que é ciência, Dona Benta? A literatura de Monteiro Lobato na abordagem de questões acerca da Natureza da Ciência. In: NORONHA, C. A.; MENDES, I. A. (Org.), Ensino de Ciências e Matemática: múltiplos enfoques na formação de professores. Campinas, SP: Mercado das Letras, Natal/RN: UFRN, 2015b.

GUERRA, A.; MENEZES, A. M. S. Literatura na física: uma possível abordagem para o ensino de ciências? In: ENCONTRO NACIONAL DE PESQUISA EM EDUCAÇÃO EM CIÊNCIAS - ENPEC, 7, 2009, Florianópolis. Anais... Florianópolis, 2009. p. 1-10.

HABIB, P. A. B. B. Eis o mundo encantado que Monteiro Lobato criou: raça, eugenia e nação. 2003. 175f. Dissertação (Mestrado em História Social) - Universidade Estadual de Campinas, Campinas, 2003.

LAJOLO, M. Monteiro Lobato: um brasileiro sob medida. 2. ed. São Paulo: Salamandra, 2006.

LAJOLO, M.; CECCANTINI, J. L. (Org.). Monteiro Lobato livro a livro: obra infantil. São Paulo: Editora UNESP; Imprensa Oficial do Estado de São Paulo, 2008.

LOBATO, M. As novas possibilidades das zonas cálidas. In: Revista do Brasil. São Paulo. v. 7, n. 29, p. 3-8, 1918.

- A Barca de Gleyre. São Paulo: Brasiliense, 1948.

. Reinações de Narizinho. São Paulo: Editora Globo, 2009.

- A reforma da natureza. São Paulo: Editora Globo, 2010a.

- A chave do tamanho. São Paulo: Editora Globo, 2010b.

MARTINS, A. F. P.; GROTO, S. R. Discutindo ciência com Monteiro Lobato. In: ENCONTRO NACIONAL DE PESQUISA EM EDUCAÇÃO, 8., 2012, Campinas. Atas... Campinas: ABRAPEC, 2012. p. 1-9.

MATTHEWS, M. R. História, Filosofia e Ensino de Ciências: a tendência atual de reaproximação. Caderno Catarinense de Ensino de Física, Florianópolis, v. 12, n. 3, p. 164-214, dez. 1995.

NATIONAL RESEARCH COUNCIL. Next generation science standards: for states, by states. Washington, D.C.: The National Academies Press, 2013.

OLIVEIRA, L. S. de; GOLDFARB, A. M. A. A literatura de Monteiro Lobato como instrumento de ensino de ciências: uma proposta de trabalho a partir da História da Ciência. História da Ciência e Ensino: construindo interfaces, São Paulo, v. 5, p. 13-21, 2012.

PENTEADO, J. R. W. Os filhos de Lobato. Rio de Janeiro: Dunya Editora, 1997.

PEREIRA, R. de B. Memórias do Visconde de Sabugosa. 2006. 93 f. Dissertação (Mestrado em Educação) - Universidade de Campinas, Campinas, 2006.

PINTO, A. A.; RABONI, P. C. de A. Concepções de ciência na literatura infantil brasileira: conhecer para explorar possibilidades. In: ENCONTRO NACIONAL DE PESQUISA EM 
EDUCAÇÃO, 5., 2005, Bauru. Atas... Bauru: ABRAPEC, 2005. p. 1-5.

SALOMÃO, S. R. Lições de Botânica: O Texto Literário no Ensino de Ciências. Ciência em Tela, Rio de Janeiro, v. 1, n. 1, p. 1-9, 2008. Disponível em: <www.cienciaemtela.nutes.ufrj.br/artigos/Salomao_2008_1.pdf>. Acesso em: 1 mar. 2012.

SANTOS, T. dos. Concepcõés de ciência nas obras de Monteiro Lobato: mapeamento e análise de termos científicos no livro Serões de Dona Benta. 2011. 125f. Dissertação (Mestrado em Educação para a Ciência) - Universidade do Estado de São Paulo, Bauru, 2011.

SILVA, C. C.; GASTAL, M. L. Ensinando ciências e ensinando a respeito das ciências. In: PAVÃO, A. C.; FREITAS, D. (Org.). Quanta ciência há no ensino de ciências. São Carlos: EduFSCar, 2011. p. 34-44.

SILVEIRA, M. P. da. O potencial de relações entre ensino de ciências e literatura por meio da obra de Monteiro Lobato. In: COLÓQUIO DE ESTUDOS LINGÜÍSTICOS E LITERÁRIOS, 4.,2010, Maringá, PR. Anais... Maringá, PR, 2010. Disponível em: <http://www.cielli.com.br/downloads/217.pdf html>. Acesso em: 24 mar. 2012.

. Literatura e Ciência: Monteiro Lobato e o ensino de química. 2013. 297f. Tese (Doutorado em Ensino de Ciências) - Universidade de São Paulo, São Paulo, 2013.

VALENTE, T. A. A chave do mundo: o tamanho. In: LAJOLO, M.; CECCANTINI, J. L. (Org.). Monteiro Lobato livro a livro: obra infantil. São Paulo: UNESP; Imprensa Oficial do Estado de São Paulo, 2008. p. 455-467.

ZANETIC, J. Física e literatura: uma possível integração no ensino. In: ENCONTRO DE PESQUISADORES EM ENSINO DE FÍSICA - EPEF, 5, 1997, Belo Horizonte. Atas... Belo Horizonte: UFMG/CECIMIG/FAE, 1997. p. 27-33.

. Física e literatura: construindo uma ponte entre as duas culturas. História, Ciências, Sańde, Manguinhos, RJ, v. 13, p. 55-70, out. 2006. Suplemento.

. Literatura e cultura científica. In: ALMEIDA, M. J. P. M.; SILVA, H. C. Linguagens, Leituras e Ensino de Ciências. Campinas: Mercado das Letras, 2007. p. 11-31.

Física ainda é cultura! In: MARTINS, A. F. P. Física ainda é cultura? São Paulo: Livraria da Física, 2009. p. 281-300.

Data Recebimento: 27/11/2014

Data de aprovação: 02/04/2015

Contato autor:

Silvia Regina Groto

Caixa Postal 94 - Tibau do Sul - Rio Grande do Norte - Brasil

CEP 59178-000

E-mail: silviagroto@hotmail.com 